Chronic Obstructive Pulmonary Diseases:

Journal of the COPD Foundation

\title{
Review
}

\section{New Therapeutic Targets for Alpha-1 Antitrypsin Deficiency}

\author{
David A. Lomas, $\mathrm{MD}, \mathrm{PhD}^{1}$
}

\begin{abstract}
Alpha-1antitrypsin deficiency (AATD) results from the intracellular polymerization and retention of mutant alpha-1antitrypsin (AAT) within the endoplasmic reticulum of hepatocytes. This causes cirrhosis whilst the deficiency of circulating AAT predisposes to early onset emphysema. This is an exciting time for researchers in the field with the development of novel therapies based on understanding the pathobiology of disease. I review here augmentation therapy to prevent the progression of lung disease and a range of approaches to treat the liver disease associated with the accumulation of mutant AAT: modifying proteostasis networks that are activated by Z AAT polymers, stimulating autophagy, small interfering RNA and small molecules to block intracellular polymerization, and stem cell technology to correct the genetic defect that underlies AATD.
\end{abstract}

Abbreviations: alpha-1 antitrypsin deficiency, AATD; alpha-1 antitrypsin, AAT; chronic obstructive pulmonary disease, COPD; forced expiratory volume in 1 second, $\mathbf{F E V}_{\mathbf{1}}$; recombinant adenovirus, rAd; recombinant adeno-associated virus, rAAV; Food and Drug Administration, FDA; small interfering RNA, siRNA; antisense, ALN; Arrowhead siRNA AAT, ARC-AAT; human-induced pluripotent stem cells, hIPSCs

Funding Support: David Lomus is funded by the Medical Research Council, Wellcome Trust, GlaxoSmithKline, the Rosetrees Trust, the Engineering and Physical Sciences Research Council and the University College London Hospitals- National Institute for Health Research, Biomedical Research Centre.

Date of Acceptance: January 8, 2018

Citation: Lomas DA. New therapeutic targets for alpha-1 antitrypsin deficiency. Chronic Obstr Pulm Dis. 2018;5(4):233-243.

doi: https://doi.org/10.15326/jcopdf.5.4.2017.0165

1 UCL Respiratory, Division of Medicine, University College London, United Kingdom

\section{Address correspondence to:}

David Lomas, MD, PhD

UCL Respiratory, Division of Medicine

Rayne Building

University College London

WC1E 6BN

London, UK

Email: d.lomas@ucl.ac.uk

\section{Keywords:}

alpha-1 antitrypsin deficiency; emphysema; cirrhosis; conformational disease; small molecules; siRNA; proteostasis; autophagy

\section{Introduction}

The serpinopathies are characterized by the misfolding and intracellular polymerization of members of the serpin (serine protease inhibitor) superfamily. ${ }^{1}$ The best characterized of the serpinopathies is alpha-1 antitrypsin deficiency (AATD). ${ }^{2}$ Ninety five percent of severe deficiency of AAT results from the Glu342Lys mutation or $\mathrm{Z}$ allele. This mutation arose approximately 2000 years ago and is found in 1 out of 25 of the North European white population with 1 out of 2000 individuals carrying 2 Z alleles (homozygotes). The $\mathrm{Z}$ mutation causes approximately $70 \%$ of the synthesised protein to be degraded by the proteasome, $15 \%-20 \%$ misfolds to form ordered intracellular polymers and 10\%-15\% folds normally and is secreted into the circulation. ${ }^{3}$ The intracellular polymers are sequestered within the endoplasmic 
reticulum as Periodic Acid Schiff-positive, diastaseresistant inclusions ${ }^{2,4}$ that are associated with neonatal hepatitis, cirrhosis and hepatocellular carcinoma. ${ }^{5}$ AAT is a major circulating antiprotease that functions to regulate the proteolytic effects of neutrophil elastase within the lung. The lack of circulating AAT predisposes the Z AAT homozygote to early onset panlobular basal emphysema, particularly in individuals who smoke tobacco. ${ }^{6}$ AATD is found in $1 \%-2 \%$ of individuals with chronic obstructive pulmonary disease (COPD)-a syndrome characterized by small airways disease and emphysema. COPD will be the third most common cause of death worldwide by 2020 .

\section{Current Therapies for Alpha-1 Antitrypsin Deficiency}

AATD was first described by Laurell and Eriksson in $1963 .^{7}$ The most effective interventions are still behavioral. $^{8}$ In particular, individuals with AATD should refrain from smoking ${ }^{6}$ and probably avoid passive exposures from dusty occupations. ${ }^{9}$ This will help to preserve lung function. Individuals with AATD should also avoid excessive consumption of alcohol and excessive weight gain (which predisposes to a fatty liver). Both are additive to the liver damage caused by AATD.

The only specific treatment for AATD is augmentation with pooled plasma AAT. ${ }^{10}$ This was launched in the United States in 1988 on the basis of biochemical data showing that infusions raised circulating levels of AAT and provided protection against proteases within the lung. ${ }^{11}$ Two randomized clinical trials failed to demonstrate that augmentation therapy reduces the rate of decline in lung function as assessed by forced expiratory volume in 1 second $\left(\mathrm{FEV}_{1}\right) .{ }^{12,13}$ However, augmentation therapy is associated with a reduction in sputum markers of inflammation ${ }^{14}$ and in the frequency of respiratory tract infections. ${ }^{15}$ The recent RAPID study funded by CSL Behring randomized 93 individuals (83 PiZZ, 2 PiSZ, 2 Z/Null, 6 other) to augmentation therapy and 87 to placebo (83 PiZZ, 0 PiSZ, 1 Z/Null, 3 other) (NCT00261833). ${ }^{16}$ They were followed for 24 months. There was no difference in the annual rate of lung density loss at total lung capacity and functional residual capacity combined between the 2 groups. However, there was a significant reduction in annual rate of lung density loss at total lung capacity in individuals who received augmentation therapy (difference $0 \cdot 74 \mathrm{~g} / \mathrm{L}$ per year [95\% confidence interval 0.06-1.42], $p=0.03$ ) but there was no difference at functional residual capacity alone (difference $0.48 \mathrm{~g} / \mathrm{L}$ per year [-0.22 to $1 \cdot 18$ ], $p=0 \cdot 18$ ). The significant benefit in one of the primary endpoints is encouraging but it is not clear how a difference in change of total lung capacity translates to clinical benefit or whether there is a particular subgroup that benefits from augmentation therapy. The study has resulted in approval for augmentation therapy in individuals with AATD by the European Medicines Agency. The United Kingdom National Institute for Clinical Excellence will now need to decide on the cost-benefit of this therapy and whether it represents value for money in the British health care system. This is important as augmentation therapy costs approximately $\$ 100,000 /$ patient/year.

End stage lung disease in individuals with AATD may be suitable for transplantation. Indeed, lung transplantation for AATD-related emphysema accounts for $3.2 \%$ of all adult lung transplants and $10 \%$ of all transplants for emphysema.

There is no specific therapy for the liver disease associated with AATD other than conservative treatment that is used for all forms of chronic liver disease, and where suitable, liver transplantation. Transplantation for AATD accounts for 3.5\% and 1.1\% of pediatric and adult liver transplants respectively.

\section{Novel Approaches to the Lung Disease Associated with Alpha-1 Antitrypsin Deficiency}

\section{Improved Alpha-1 Antitrypsin Replacement Therapy}

Several approaches have been adopted to replace circulating AAT and therefore, protect against progressive emphysema that characterizes AATD. These include giving higher doses of intravenous AAT (120 rather than $60 \mathrm{mg} / \mathrm{kg}$ per week), modifying recombinant AAT to increase its stability and delivering AAT as an inhaled preparation. The inhaled route requires significantly less material to inhibit neutrophil elastase but needs to access the alveolar space that is destroyed in emphysema. An alternative strategy is to use non-viral gene transfer, gamma-retrovirus, recombinant adenovirus ( $\mathrm{rAd}$ ), and recombinant adeno-associated virus (rAAV) vectors 
to express AAT. These may be targeted to the lung epithelium as well as to hepatocytes, pleural and muscle cells. The challenge is to achieve long-term expression of large quantities of AAT. A phase II clinical trial that used rAAV vectors achieved only $3 \%-5 \%$ of the target level of AAT. ${ }^{17}$

\section{Other Treatments for Lung Disease Associated with Alpha-1 Antitrypsin Deficiency}

Individuals with AATD-related emphysema should receive the same therapies as individuals with COPD who have normal levels of AAT. These include: inhaled short- and long-acting beta2-agonists, inhaled corticosteroids and long-acting anti-cholinergics based on patient symptoms, lung function impairment and exacerbation frequency. Treatment with macrolide antibiotics and roflumilast should be considered for patients with frequent exacerbations. Individuals with AATD-related emphysema should also receive pulmonary rehabilitation and vaccination against pneumococcus and circulating strains of influenza. Attempts to regenerate alveoli damaged by emphysema with retinoic acid were effective in rat models of disease ${ }^{18}$ but not in a clinical trial in humans. ${ }^{19}$ The most effective therapy for individuals with severe airflow obstruction is lung transplantation. Younger patients with less comorbidity may have a higher benefit (increased survival) from double lung rather than single lung transplant. However, the supply of organs is limited. Thus, individuals with AATD may be considered for lung volume reduction surgery and endobronchial lung volume reduction as a bridge to surgery or for those who are not candidates for a major operation. Lung volume reduction surgery in individuals with AATD is inferior to that in patients with COPD and normal levels of AAT. ${ }^{20,21}$ There appears to be a smaller increase in $\mathrm{FEV}_{1}$ after surgery and a shorter duration of benefit.

Endobronchial lung volume reduction is performed by one-way valves placed by flexible bronchoscope. The data are limited to case series. The insertion of one-way endobronchial valves in 15 individuals with AATD resulted in an increase in $\mathrm{FEV}_{1}$ of $54 \%$ after 12 months in 12 of the individuals, quality of life was much improved and 2 individuals were taken off oxygen therapy. There was no significant deterioration in lung function during the 4-year follow-up. ${ }^{22}$ However, there were complications in 3 of the individuals: 1 developed a pneumothorax and had valve displacement and subsequent removal, 1 coughed up the valves after 2 months and 1 developed repeated and severe pneumonia and the valves had to be removed.

\section{Novel Approaches to the Liver Disease Associated with Alpha-1 Antitrypsin Deficiency}

\section{Modifying Pathways and Proteostasis Networks That are Activated by Z Alpha-1 Antitrypsin Polymers}

A surprising feature of the accumulation of $\mathrm{Z}$ AAT polymers as inclusions within hepatocytes is that, despite marked distortion of the endoplasmic reticulum architecture, they do not activate the unfolded protein response when expressed in cell models of disease. ${ }^{23-26}$ However, they do activate NF-kB proteins and display a more marked unfolded protein response when stressed with a second hit. ${ }^{24,26}$ This results from AAT polymers increasing the viscosity within the endoplasmic reticulum which reduces the mobility of chaperones and hence their ability to neutralize the effect of a second insult. ${ }^{26}$

The findings are different when assessed by gene profiling of hepatocytes from a transgenic mouse model expressing human $\mathrm{Z} \mathrm{AAT}{ }^{27}$ In this case, there was upregulation of genes associated with the unfolded protein response and cellular stress genes including c-JUN. $^{28}$ The expression of Z AAT upregulates JNK and c-JUN. Genetic ablation of JNK1 or JNK2 decreases AAT levels in vivo by reducing c-JUN mediated expression of AAT. Thus, JNK may be a therapeutic target for the liver disease associated with AATD. The difficulty is that JNK has pleotropic effects and is widely expressed in vivo. Thus, an inhibitor of JNK is likely to have off-target effects. Nevertheless, if validated in other studies, JNK may prove useful as a biomarker to develop agents that suppress the intracellular polymerization (and accumulation) of $\mathrm{Z}$ AAT. $^{29}$

The intracellular polymerization of Z AAT occurs in the context of chaperone-mediated folding, proteasomal degradation and a cooperative proteostatic network. Chemical chaperones such as trimethylamine $\mathrm{N}$-oxide, glycerol, erythritol, trehalose, and its breakdown product glucose, have been evaluated for their ability to stabilize the folding of $\mathrm{Z}$ AAT in vitro. ${ }^{30,31}$ Fourphenylbutyric acid is effective in increasing the secretion of functionally active $Z$ AAT in a cell and 
animal model of disease ${ }^{32}$ but was not effective when assessed in a clinical trial in individuals with Z AATD. ${ }^{33}$ An alternative approach is to target the proteostasis network that responds to the expression of $\mathrm{Z}$ AAT. Defining this network may lead to the identification of key "nodes", signaling pathways and molecules that may be manipulated to increase folding of Z AAT to the monomeric protein and so facilitate secretion. This is illustrated by suberoylanilide hydroxamic acid which increases the secretion of Z AAT from epithelial cell lines by inhibition of histone deacetylase $7 .{ }^{34}$ Such an approach has yet to be evaluated in animal models of disease or in humans. However, it provides support for small molecule or siRNA-based screens of cell lines or model organisms (for example in C. elegans and drosophila) to identify other pathways that are up or down regulated following the expression of $Z$ or other mutants of AAT. These pathways may be targeted for pharmacological intervention to reduce intracellular inclusions and/or increase the secretion of the mutant protein.

\section{Stimulating Autophagy to Clear Intracellular Inclusions}

The landmark paper by Hidvegi and colleagues demonstrated that the Food and Drug Administration (FDA)-approved drug, carbamazepine, can stimulate proteasomal and autophagy pathways to clear intracellular polymers of AAT. 35 Carbamazepine is widely usually used to treat epilepsy. It was selected as it stimulates autophagy by a pathway that is independent of mTOR (mammalian target of rapamycin) and is known to enhance autophagic degradation of polyglutamine repeats. Moreover, the safety profile is well known in humans. Administration of large doses of carbamazepine (10-20 times the recommended dose for individuals with epilepsy) to a transgenic mouse model expressing human Z AAT reduced the intrahepatic PAS positive inclusions of $Z$ AAT within 2 weeks of therapy and reversed hepatic fibrosis. These findings support the development of autophagy enhancers to treat AATD and the assessment of carbamazepine in a randomized, controlled clinical trial in individuals with severe liver disease (NCT01379469). ${ }^{36}$ In this study, participants are started on $400 \mathrm{mg} /$ day carbamazepine and the dose increased weekly by $200 \mathrm{mg} /$ day until a stable therapeutic concentration is reached with a dose not exceeding $1200 \mathrm{mg} /$ day (or $1000 \mathrm{mg} /$ day in participants less than 15 years of age). The placebo group receives encapsulated tablets without carbamazepine. The primary endpoint is a significant reduction in the hepatic accumulation of $\mathrm{Z}$ AAT.

It is uncertain whether the effects will be seen at much lower doses of carbamazepine than those used in transgenic mice and whether the human liver has the same capacity to recover as that of the mouse. However, even if the trial is unsuccessful, there is impetus to assess other FDA-approved drugs (such as lithium and rapamycin) that also stimulate autophagy in cell and animal models of disease. ${ }^{37}$ Rapamycin targets $\mathrm{mTOR}$ and so may have synergistic properties with agents such as carbamazepine and lithium that act by pathways that are independent of $\mathrm{mTOR} .^{38}$

Rapamycin (sirolimus) has been evaluated in the transgenic mouse that overexpresses Z AAT. ${ }^{39}$ Daily dosing had no effect on autophagy. However, weekly dosing increased the number of autophagic vacuoles, reduced the accumulation of intrahepatic polymerized $Z$ AAT and reduced markers of hepatocellular injury including hepatic fibrosis and cleavage of caspase 12. ${ }^{39}$ An alternative approach is to drive autophagy with viral vectors that overexpress the autophagy regulator transcription factor EB. This also reduced the accumulation of $\mathrm{Z}$ AAT, hepatocyte apoptosis and fibrosis in the liver of the transgenic mouse that expresses $Z$ AAT. $^{40}$ It also decreased activation of hepatic NFkB and IL-6 that drive the expression of $Z$ AAT. Both rapamycin and overexpression of transcription factor $E B$ reduce the burden of intracellular AAT and decrease hepatic fibrosis in a mouse model of disease. The challenge now is to demonstrate efficacy of these approaches in humans.

\section{Small Interfering RNA to Silence the Expression of Z Alpha-1 Antitrypsin}

The most exciting recent therapeutic intervention for the liver disease associated with AATD is the development of RNA interference- based approaches to silence Z AAT synthesis within hepatocytes. ${ }^{41,42}$ This is being led by 2 biotechnology companies: Arrowhead Research Corporation and Alnylam Pharmaceuticals, Inc. Small interfering RNA (siRNA) constructs have been targeted against hepatocyte mRNA encoding human AAT. The administration of these agents reduces soluble and aggregated hepatic AAT and circulating levels of AAT in the transgenic mouse model of disease. ${ }^{43}$ siRNA constructs arrest the progression 
of liver disease in transgenic mice following shortterm treatment and reverse liver disease after longterm treatment. Their administration to non-human primates reduced circulating levels of normal AAT by approximately $80 \%$.

siRNA therapy for AATD-related liver disease has been evaluated in a phase I/II clinical trial (NCT02503683). ${ }^{44}$ This was a randomized, singleblind, placebo-controlled, single ascending dose and multiple dose study that aimed to enroll 66 participants. It started in July 2015 and aimed to complete in April 2017. The study assessed tolerability, pharmacokinetics and pharmacodynamics of subcutaneously administered antisense (ALN) AAT in healthy adult participants and individuals with $\mathrm{Z}$ AATD liver disease. The primary outcome was the safety of siRNA targeting ALN-AAT as assessed by the proportion of participants experiencing adverse events, serious adverse events, and adverse events leading to discontinuation of the study drug. The secondary outcome was the effect of siRNA targeting AAT on serum levels of AAT. Preliminary reports suggest that the administration of ALN-AAT caused a dose-dependent and durable knockdown of the target protein. ${ }^{45}$ A single dose of ALN-AAT ( $6 \mathrm{mg} / \mathrm{kg}$ ) knocked down up to $88.9 \%$ of circulating AAT with a mean maximal knockdown of $83.9 \pm 2.6 \%$. Monthly treatment resulted in a mean knockdown of serum AAT of $75.0 \pm 1.2 \%$ at approximately 6 months. However, there was liver enzyme elevation at the highest dose in 3 patients and so the candidate ALN-AAT siRNA has been terminated. A new candidate is being developed.

The multi-center, randomized, placebo-controlled, double-blind, single-dose-escalation first-in-human, Phase 1 study in healthy volunteers and AATD patients to evaluate the Arrowhead siRNA AAT (ARC-AAT) enrolled 65 participants but was terminated in January 2017 (NCT02363946). ${ }^{46}$ Data presented at the 2016 Annual Meeting of the American Association for the Study of Liver Disease reported that ARC-AAT was well tolerated and induced deep and durable reduction of the target AAT protein (up to 90\%). ${ }^{47}$ The followup study, an open-label, multi-dose, Phase 2 study to determine the safety, tolerability and effect on circulating and intrahepatic AAT levels of ARC-AAT as evidenced by changes in liver biopsy in patients with AATD has been withdrawn (NCT02900183). ${ }^{48}$ Further details of this program are awaited.

\section{Small Molecule Approach to Block Intracellular Polymerization}

AATD results from the retention of polymers of mutant AAT within the endoplasmic reticulum of hepatocytes. ${ }^{2,4}$ Polymers form as a result of the $Z$ mutation perturbing protein folding, and the structure of the folded protein, to form an unstable intermediate that we termed $M^{* 49}$ in which $\beta$-sheet $A$ opens ${ }^{2,49}$ and the upper part of helix F unwinds. ${ }^{50-52}$ The loop of another molecule inserts into the patent $\beta$-sheet A to form a loop-sheet dimer, which extends to form longer chains of loop-sheet polymers. ${ }^{2,49,53}$ Ninetyfive percent of severe deficiency of AAT results from the $\mathrm{Z}$ allele (Glu342Lys) but hepatic inclusions of intracellular polymers and profound plasma deficiency are also seen in 3 other mutants of AAT: Siiyama (Ser53Phe), ${ }^{54}$ Mmalton ( $\Delta$ Phe 52$)^{55}$ and King's (His334Asp). ${ }^{4}$ We have shown that this process of polymerization also explains the deficiency of the mild S (Glu264Val), I (Arg39Cys), Queen's (Lys 154Asn) and Baghdad (Ala336Pro) alleles of AAT. ${ }^{52,56-58}$ However, the rate of polymer formation is much slower in keeping with mild plasma deficiency and the absence of liver disease.

Understanding the pathophysiology of AAT polymerization has allowed the development of novel strategies to block polymerization with the aim of curing AATD. Initial studies showed that peptides that are homologous to the reactive centre loop can bind to AAT and block polymerisation in vitro. $2,59,60$ Smaller peptides were identified that had a similar effect but with greater specificity for $Z$, rather than the wildtype M, AAT. ${ }^{61-64}$ However, it is not clear how these peptides can be delivered to hepatocytes in vitro, let alone in in vivo.

An alternative approach is to use our understanding of the structural biology of polymers to develop small molecules that block polymerization. The crystal structure of AAT identified a hydrophobic pocket that is bounded by strand $2 A$ and helices $D$ and $E .{ }^{65}$ The cavity is available in the monomeric, native protein but is filled by movement of $\beta$-sheet $A$ as it accepts an exogenous reactive loop peptide during polymerization. Polymer formation was reduced when this cavity was filled by the Thr114Phe mutation on strand 2 of $\beta$-sheet $A$. This mutation also increased the secretion of Z AAT from a Xenopus oocyte expression system. ${ }^{66,67}$ Virtual ligand screening against this cavity identified 66 compounds as potential binders. ${ }^{68}$ 
Some of these blocked polymerization in vitro and in cell models that express Z AAT. ${ }^{68}$ This proof of principle resulted in a "Discovery Partnership with Academia" partnership with GlaxoSmithKline to develop small molecules that are effective in blocking polymerization as an approach to treating AATD. ${ }^{69}$

\section{Intrabodies as a Strategy to Block Intracellular Polymerization and Increase Secretion of $Z$ Alpha-1 Antitrypsin}

Monoclonal antibody technology has allowed the identification of antibodies that detect the polymeric ${ }^{4}$ and latent ${ }^{70}$ conformers of AAT and antibodies that can block ${ }^{71}$ and accelerate ${ }^{72}$ polymer formation. The 4B12 monoclonal antibody blocked AAT polymerization at a 1:1 molar ratio in vitro by binding to an epitope that encompasses residues Glu32, Glu39 and His43 on helix A and Leu306 on helix I. ${ }^{73}$ This antibody identified a region that may be targeted for the rational design of ligands that can dynamically influence AAT polymerization. Moreover, the expression of a single chain-variable-fragment intrabody of mAb4B12 reduced the intracellular polymerization of $\mathrm{Z} A \mathrm{AAT}$ by $60 \%$ and increased the secretion of $\mathrm{Z}$ AAT that retained inhibitory activity against neutrophil elastase. ${ }^{71}$ This demonstrates that monoclonal antibodies can block the transition of Z AAT to aberrant polymers without compromising inhibitory activity of the protein.

\section{Cell Therapy for Alpha-1 Antitrypsin Deficiency}

Hepatocytes that express wildtype AAT have a competitive advantage over cells that express the $\mathrm{Z}$ protein. Wild-type donor hepatocytes replaced $20 \%-98 \%$ of host hepatocytes in transgenic mice expressing human Z AAT. ${ }^{74}$ Repopulation was accelerated by injection of an adenovirus vector expressing hepatocyte growth factor but spontaneous repopulation with engrafted hepatocytes occurred in the transgenic mice even in the absence of severe liver injury. Donor cells replaced both globule-containing and globule-devoid cells, indicating that both types of host hepatocytes have impaired proliferation relative to wildtype hepatocytes. These results suggest that wildtype hepatocyte transplantation may be therapeutic for individuals with Z AAT liver disease.

Dermal fibroblasts have been isolated from individuals with AATD and used to generate patientspecific human-induced pluripotent stem cell
(hIPSCs) lines. These hIPSC lines were differentiated into hepatocyte-like cells using a novel and simple 3-step differentiation protocol in chemically-defined conditions. The patient-specific hIPSC derived hepatocytes recapitulate protein misfolding and the formation of pathological polymers that characterize AATD. ${ }^{75,76}$ They were also used in a proof of concept study to show that the combination of engineered Zinc finger nucleases and a piggyBac donor vector gene editing technique can be used to restore normal structure, function and secretion of AAT in subsequently derived liver cells. ${ }^{77}$ The derived hepatocytes secreted AAT when introduced into a mouse model of liver injury. ${ }^{77}$ The challenge is to obtain cells that are more like the fully-differentiated hepatocyte and which are safe to use in humans.

More recently Baligar and colleagues ${ }^{78}$ showed that the intra-splenic injection of LSK cells (Lineage negative, Sca-1 positive, C-Kit negative) into the transgenic mouse model of AATD could reduce the numbers of AAT globule-containing hepatocytes in the recipient liver. This cell therapy improved proliferation of host globule-devoid hepatocytes and donor derived cells and partially improved liver pathology as assessed by inflammatory response, fibrosis and apoptotic hepatocyte death. The findings suggest transplantation of allogeneic bone marrow derived stromal cells may be an effective therapy for individuals with AATD. If correct, then this offers the potential to recover normal levels of secreted AAT and thereby, simultaneously treat the associated lung disease.

\section{Summary}

Current respiratory management of individuals with AATD involves the routine care offered to all patients with COPD along with augmentation therapy. However, augmentation therapy is expensive and the cost-benefit ratio, and the decision of which individuals should be treated, is not clear. Some individuals may benefit from lung volume reduction surgery and the placement of endobronchial valves although the benefit from lung volume reduction surgery may be short-lived and there is relatively little data on long-term outcomes following valve placement. The management of the liver disease associated with AATD is currently limited to supportive measures. However, there is real promise with the development of siRNA technology and agents 
that block the formation of polymers or stimulate pathways that accelerate their clearance.

\section{Declaration of Interests}

DAL is working with GlaxoSmithKline to develop small molecules that block the intracellular polymerization of AAT. 


\section{References}

1. Lomas DA, Mahadeva R. Alpha-1-antitrypsin polymerisation and the serpinopathies: pathobiology and prospects for therapy. J Clin Invest. 2002;110(11):1585-1590.

doi: https://doi.org/10.1172/JCI0216782

2. Lomas DA, Evans DL, Finch JT, Carrell RW. The mechanism of Z a1-antitrypsin accumulation in the liver. Nature. 1992;357:605607. doi: https://doi.org/10.1038/357605a0

3. Kröger H, Miranda E, MacLeod I, et al. Endoplasmic reticulumassociated degradation (ERAD) and autophagy cooperate to degrade polymerogenic mutant serpins. J Biol Chem. 2009;284(34):22793-22802.

doi: https://doi.org/10.1074/jbc.M109.027102

4. Miranda E, Pérez J, Ekeowa, et al. A novel monoclonal antibody to characterise pathogenic polymers in liver disease associated with a1-antitrypsin deficiency. Hepatology. 2010;52:1078-1088. doi: https://doi.org/10.1002/hep.23760

5. Eriksson S, Carlson J, Velez R. Risk of cirrhosis and primary liver cancer in alpha1-antitrypsin deficiency. $N$ Engl J Med. 1986;314:736-739.

doi: https://doi.org/10.1056/NEJM198603203141202

6. Larsson C. Natural history and life expectancy in severe alpha 1antitrypsin deficiency, PiZ. Acta Med Scand. 1978;204(1-6):345351. doi: https://doi.org/10.1111/j.0954-6820.1978.tb08452.x

7. Laurell C-B, Eriksson S. The electrophoretic a1-globulin pattern of serum in a1-antitrypsin deficiency. Scand J Clin Lab Invest. 1963;15(2):132-140.

doi: https://doi.org/10.1080/00365516309051324

8. Lomas DA, Hurst JR, Gooptu B. Update on alpha-1 antitrypsin deficiency: new therapies. J Hepatol. 2016;65(2):413-424.

doi: https://doi.org/10.1016/j.jhep.2016.03.010

9. Mayer NS, Stoller JK, Bartelson BB, Ruttenber AJ, Sandhaus RA, Newman LS. Occupational exposure risks in Individuals with PI*Z a1-antitrypsin deficiency. Am J Respir Crit Care Med. 2000;162(2):553-558.

doi: https://doi.org/10.1164/ajrccm.162.2.9907117

10. Stoller JK, Aboussouan LS. Alpha-1 antitrypsin deficiency. Lancet. 2005;365(9478):2225-2236.

doi: https://doi.org/10.1016/S0140-6736(05)66781-5

11. Wewers MD, Casolaro MA, Sellers SE, et al. Replacement therapy for alpha 1-antitrypsin deficiency associated with emphysema. $N$ Engl J Med. 1987;316:1055-1062.

doi: https://doi.org/10.1056/NEJM198704233161704

12. Dirksen A, Dijkman JH, Madsen F, Stoel B, Hutchison DCS, Ulrik CS, et al. A randomised clinical trial of $\alpha 1-$ antitrypsin augmentation therapy. Am J Resp Crit Care Med. 1999;160(5):1468-1472.

doi: https://doi.org/10.1164/ajrccm.160.5.9901055
13. Dirksen A, Piitulainen E, Parr DG, et al. Exploring the role of CT densitometry: a randomised study of augmentation therapy in alpha1-antitrypsin deficiency. Eur Respir J. 2009; 33:1345-1353. doi: https://doi.org/10.1183/09031936.00159408

14. Stockley RA, Bayley DL, Unsal I, Dowson LJ. The effect of augmentation therapy on bronchial inflammation in alpha1-antitrypsin deficiency. Am J Respir Crit Care Med. 2002;165(11):1494-1498.

doi: https://doi.org/10.1164/rccm.2109013

15. Lieberman J. Augmentation therapy reduces frequency of lung infections in antitrypsin deficiency: a new hypothesis with supporting data. Chest. 2000; 118(5):1480-1485. doi: https://doi.org/10.1378/chest.118.5.1480

16. Chapman KR, Burdon JG, Piitulainen E, et al. Intravenous augmentation treatment and lung density in severe a1 antitrypsin deficiency (RAPID): a randomised, double-blind, placebo-controlled trial. Lancet. 2015;386(9991):360-368. doi: https://doi.org/10.1016/S0140-6736(15)60860-1

17. Mueller C, Flotte TR. Gene-based therapy for alpha-1 antitrypsin deficiency. COPD. 2013;10(Sup 1):44-49.

doi: https://doi.org/10.3109/15412555.2013.764978

18. Massaro GD, Massaro D. Retinoic acid treatment abrogates elastase-induced pulmonary emphysema in rats. Nature Med. 1997;3(6):675-677.

doi: https://doi.org/10.1038/nm0697-675

19. Stolk J, Stockley RA, Stoel BC, et al. Randomized controlled trial for emphysema with a selective agonist of the gamma type retinoic acid receptor. Eur Respir J. 2012;40:306-312. doi: https://doi.org/10.1183/09031936.00161911

20. Stoller JK, Gildea TR, Ries AL, Meli YM, Karafa MT, National Emphysema Treatment Trial Research Group. Lung volume reduction surgery in patients with emphysema and alpha-1 antitrypsin deficiency. Ann Thorac Surg. 2007;83(1):241-251. doi: https://doi.org/10.1016/j.athoracsur.2006.07.080

21. Donahue JM, Cassivi SD. Lung volume reduction surgery for patients with alpha-1 antitrypsin deficiency emphysema. Thorac Surg Clin. 2009;19(2):201-208.

doi: https://doi.org/10.1016/j.thorsurg.2009.02.002

22. Hillerdal G, Mindus S. One- to four-year follow-up of endobronchial lung volume reduction in alpha-1-antitrypsin deficiency patients: a case series. Respiration. 2014;88(4):320328. doi: https://doi.org/10.1159/000365662

23. Graham KS, Le A, Sifers RN. Accumulation of the insoluble PiZ variant of human $\alpha 1$-antitrypsin within the hepatic endoplasmic reticulum does not elevate the steady-state level of grp78/BiP. $J$ Biol Chem. 1990;265(33):20463-20468. 
24. Lawless MW, Greene CM, Mulgrew A, Taggert CC, O’Neill SJ, McElvaney NG. Activation of endoplasmic reticulum-specific stress responses associated with the conformational disease $\mathrm{Z}$ a1-antitrypsin deficiency. J Immunol. 2004;172:5722-5726. doi: https://doi.org/10.4049/jimmunol.172.9.5722

25. Hidvegi T, Mirnics K, Hale P, Ewing M, Beckett C, Perlmutter DH. Regulator of $G$ signaling 16 is a marker for the distinct $E R$ stress state associated with aggregated mutant alpha 1-antitrypsin Z in the classical form of a1-antitrypsin deficiency. J Biol Chem. 2007;282: 27769-27780.

doi: https://doi.org/10.1074/jbc.M704330200

26. Ordnez A, Snapp EL, Tan L, Miranda E, Marciniak SJ, Lomas DA. Endoplasmic reticulum polymers impair luminal protein mobility and sensitize to cellular stress in alpha1-antitrypsin deficiency. Hepatology. 2013;57(5):2049-2060.

doi: https://doi.org/10.1002/hep.26173

27. Carlson JA, Barton Rogers B, Sifers RN, et al. Accumulation of PiZ a1-antitrypsin causes liver damage in transgenic mice. $J$ Clin Invest. 1989;83:1183-1190. doi: https://doi.org/10.1172/JCI113999

28. Pastore N, Attanasio S, Granese B, et al. Activation of JNK pathway aggravates proteotoxicity of hepatic mutant $\mathrm{Z}$ alpha 1antitrypsin. Hepatology. 2017;65(6). doi: https://doi.org/10.1002/hep.29035

29. Rashid ST, Lomas DA. Liver: Taking out the JuNK to treat a1antitrypsin AAT deficiency. Nat Rev Gastroenterol Hepatol. 2017;14:201-202. doi: https://doi.org/10.1038/nrgastro.2017.22

30. Devlin GL, Parfrey H, Tew DJ, Lomas DA, Bottomley SP. Prevention of polymerization of $\mathrm{M}$ and $\mathrm{Z}$ a1-antitrypsin ( $\alpha 1-\mathrm{AT}$ ) with Trimethylamine N-Oxide. Implications for the treatment of a1-AT deficiency. Am J Respir Cell Mol Biol. 2001;24(6):727-732. doi: https://doi.org/10.1165/ajrcmb.24.6.4407

31. Sharp LK, Mallya M, Kinghorn KJ, et al. Sugar and alcohol molecules provide a therapeutic strategy for the serpinopathies that cause dementia and cirrhosis. FEBS J. 2006;273(11):25402552. doi: https://doi.org/10.1111/j.1742-4658.2006.05262.x

32. Burrows JAJ, Willis LK, Perlmutter DH. Chemical chaperones mediate increased secretion of mutant a1-antitrypsin ( $\alpha 1$ AT) Z: a potential pharmacologcial strategy for prevention of liver injury and emphysema. Proc Natl Acad Sci USA. 2000;97 (4):1796-1801. doi: https://doi.org/10.1073/pnas.97.4.1796

33. Teckman JH. Lack of effect of oral 4-phenylbutyrate on serum alpha-1-antitrypsin in patients with alpha-1-antitrypsin deficiency: a preliminary study. J Pediatr Gastroenterol Nutr. 2004;39(1):34-37.

doi: https://doi.org/10.1097/00005176-200407000-00007
34. Bouchecareilha M, Hutta DM, Szajnera P, Flotte TR, Balch WE. Histone Deacetylase inhibitor (HDACi) Suberoylanilide Hydroxamic Acid (SAHA) mediated correction of alpha-1 antitrypsin deficiency. J Biol Chem. 2012;287 (45):38265-38278. doi: https://doi.org/10.1074/jbc.M112.404707

35. Hidvegi T, Ewing M, Hale $\mathrm{P}$, et al. An autophagy-enhancing drug promotes degradation of mutant alpha1-antitrypsin $\mathrm{Z}$ and reduces hepatic fibrosis. Science. 2010;329(5988):229-232. doi: https://doi.org/10.1126/science.1190354

36. National Institutes of Health. Carbamazepine in severe liver disease due to alpha-1 antitrypsin deficiency (CBZ). Clinicaltrials.gov website. https://clinicaltrials.gov/ct2/show/ NCT01379469. Published 2011. Accessed January 2018.

37. Zhang L, Yu J, Pan H, et al. Small molecule regulators of autophagy identified by an image-based high-throughput screen. Proc Natl Acad Sci USA. 2007;104(48):19023-19028. doi: https://doi.org/10.1073/pnas.0709695104

38. Sarkar S, Floto RA, Berger Z, et al. Lithium induces autophagy by inhibiting inositol monophosphatase. J Cell Biol. 2005;170(7):1101-1111.

doi: https://doi.org/10.1083/jcb.200504035

39. Kaushal S, Annamali M, Blomenkamp K, et al. Rapamycin reduces intrahepatic alpha-1-antitrypsin mutant $Z$ protein polymers and liver injury in a mouse model. Exp Biol Med (Maywood). 2010;235(6):700-709.

doi: https://doi.org/10.1258/ebm.2010.009297

40. Pastore N, Ballabio A, Brunetti-Pierri N. Autophagy master regulator TFEB induces clearance of toxic SERPINA1/a-1antitrypsin polymers. Autophagy. 2013;9(7):1094-1096. doi: https://doi.org/10.4161/auto.24469

41. Wooddell CI, Blomenkamp KS, Kanner S, et al. A hepatocytetargeted RNAi-based treatment for liver disease associated with alpha-1-antitrypsin deficiency. Paper presented at: 65th Annual Meeting of the American Association for the Study of Liver Diseases; November 7-11, 2014; Boston, MA

42. Sehgal A, Blomenkamp KS, Qian K, et al. Pre-clinical evaluation of ALN-AAT to ameliorate liver disease associated with alpha1-antitrypsin deficiency. Gastroenterology. 2015;148(4): S-975.

43. Guo S, Booten SL, Aghajan M, et al. Antisense oligonucleotide treatment ameliorates alpha-1 antitrypsin-related liver disease in mice. J Clin Invest. 2014;124(1):251-261. doi: https://doi.org/10.1172/JCI67968

44. National Institutes of Health. A study of an investigational drug, ALN-AAT, in healthy adult subjects and patients with ZDD type alpha-1 antitrypsin deficiency liver disease. Clinical trials. gov website. https://clinicaltrials.gov/ct2/show/NCT02503683 Published 2015. Accessed January 2018. 
45. Fierce Biotech. Alnylam down as it halts development for RNAi liver disease candidate. Fierce Biotech website. www.fiercebiotech.com/biotech/alnylam-down-as-it-haltsdevelopment-for-mai-liver-disease-candidate

Published September 2016. Accessed January 2018.

46. National Institutes of Health. A study of ARC-AAT in healthy volunteer subjects and patients with alpha-1 antitrypsin deficiency (AATD). Clinical Trials.gov website. https:// clinicaltrials.gov/ct2/show/NCT02363946

Published 2015. Accessed January 2018.

47. Arrowhead Pharmaceuticals presents new data on ARC-AAT [press release]. Pasadena, CA: Business Wire; November 14, 2016. http://ir.arrowheadpharma.com/news-releases/news-relea se-details/arrowhead-pharmaceuticals-presents-new-data-arcaat. Accessed January 2018.

48. National Institutes of Health. Safety, tolerability and effect of ARC-AAT injection on circulating and intrahepatic alpha-1 antitrypsin levels. Clinical Trials.gov website. https:// clinicaltrials.gov/ct2/show/NCT02900183 Published September 2016. Updated May 2017. Accessed January 2018.

49. Dafforn TR, Mahadeva R, Elliott PR, Sivasothy P, Lomas DA. A kinetic mechanism for the polymerisation of $\alpha 1$-antitrypsin. $J$ Biol Chem. 1999;274:9548-555.

doi: https://doi.org/10.1074/jbc.274.14.9548

50. Gooptu B, Hazes B, Chang W-SW, et al. Inactive conformation of the serpin $\alpha 1$-antichymotrypsin indicates two stage insertion of the reactive loop; implications for inhibitory function and conformational disease. Proc Natl Acad Sci USA. 2000;97(1):6772. doi: https://doi.org/10.1073/pnas.97.1.67

51. Gooptu B, Miranda E, Nobeli I, et al. Crystallographic and cellular characterisation of two mechanisms stabilising the native fold of alpha-1-antitrypsin: implications for disease and drug design. J Mol Biol. 2009;387(4):857-868. doi: https://doi.org/10.1016/j.jmb.2009.01.069

52. Nyon MP, Segu L, Cabrita LD, et al. Structural dynamics associated with intermediate formation in an archetypal conformational disease. Structure. 2012;20(3):504-512. doi: https://doi.org/10.1016/j.str.2012.01.012

53. Ekeowa UI, Freekeb J, Miranda E, et al. Defining the mechanism of polymerization in the serpinopathies. Proc Natl Acad Sci USA. 2010;107(40):17146-17151. doi: https://doi.org/10.1073/pnas.1004785107

54. Lomas DA, Finch JT, Seyama K, Nukiwa T, Carrell RW. Alpha-1antitrypsin Siiyama (Ser53Phe); further evidence for intracellular loop-sheet polymerisation. J Biol Chem. 1993;268:15333-15335.

55. Lomas DA, Elliott PR, Sidhar SK, et al. Alpha1-antitrypsin Mmalton (52Phe deleted) forms loop-sheet polymers in vivo: evidence for the $\mathrm{C}$ sheet mechanism of polymerisation. $J$ Biol Chem. 1995;270(28): 16864-16870.

doi: https://doi.org/10.1074/jbc.270.28.16864
56. Elliott PR, Stein PE, Bilton D, Carrell RW, Lomas DA. Structural explanation for the dysfunction of $\mathrm{S}$ a1-antitrypsin. Nat Struct Biol. 1996;3(10):910-911.

doi: https://doi.org/10.1038/nsb1196-910

57. Mahadeva R, Chang W-SW, Dafforn TR, et al. Heteropolymerisation of S, I and Z a1-antitrypsin and liver cirrhosis. J Clin Invest. 1999;103:999-1006. doi: https://doi.org/10.1172/JCI4874

58. Haq I, Irving JA, Saleh AD, et al. Deficiency mutations of a1-antitrypsin differentially affect folding, function and polymerization. Am J Resp Cell Mol Biol. 2016;2016(1):71-80. doi: https://doi.org/10.1165/rcmb.2015-0154OC

59. Lomas DA, Evans DL, Stone SR, Chang W-SW, Carrell RW. Effect of the $\mathrm{Z}$ mutation on the physical and inhibitory properties of a1-antitrypsin. Biochemistry. 1993;32:500-508. doi: https://doi.org/10.1021/bi00053a014

60. Skinner R, Chang W-SW, Jin L, et al. Implications for function and therapy of a $2.9 \AA$ structure of binary-complexed antithrombin. $J$ Mol Biol. 1998;283(1):9-14.

doi: https://doi.org/10.1006/jmbi.1998.2083

61. Mahadeva R, Dafforn TR, Carrell RW, Lomas DA. Six-mer peptide selectively anneals to a pathogenic serpin conformation and blocks polymerisation: implications for the prevention of $\mathrm{Z}$ a1-antitrypsin related cirrhosis. J Biol Chem. 2002;277(9):67716774. doi: https://doi.org/10.1074/jbc.C100722200

62. Parfrey H, Dafforn TR, Belorgey D, Lomas DA, Mahadeva R. Inhibiting polymerisation: new therapeutic strategies for $\mathrm{Z}$ a1-antitrypsin related emphysema. Am J Respir Cell Mol Biol. 2004;31(2):133-139.

doi: https://oi.org/10.1165/rcmb.2003-02760C

63. Zhou A, Stein PE, Huntington JA, Sivasothy P, Lomas DA, Carrell RW. How small peptides block and reverse serpin polymerization. J Mol Biol. 2004;342(3):931-941. doi: https://doi.org/10.1016/j.jmb.2004.07.078

64. Nyon MP, Prentice T, Day J, et al. An integrative approach combining ion mobility mass spectrometry, X-ray crystallography and NMR spectroscopy to study the conformational dynamics of a1-antitrypsin upon ligand binding. Protein Sci. 2015;24:13011312. doi: https://doi.org/10.1002/pro.2706

65. Elliott PR, Pei XY, Dafforn TR, Lomas DA. Topography of a 2.0A structure of $\alpha 1$-antitrypsin reveals targets for rational drug design to prevent conformational disease. Protein Science. 2000;9:1274-1281. doi: https://doi.org/10.1110/ps.9.7.1274

66. Parfrey H, Mahadeva R, Ravenhill NA, et al. Targeting a surface cavity of $\alpha 1$-antitrypsin to prevent conformational disease. J Biol Chem. 2003;278(35):33060-33066.

doi: https://doi.org/10.1074/jbc.M302646200 
67. Gooptu B, Lomas DA. Conformational pathology of the serpins -themes, variations and therapeutic strategies. Annu Rev Biochem. 2009;78:147-176.

doi: https://doi.org/10.1146/annurev.biochem.78.082107.133320

68. Mallya M, Phillips RL, Saldanha SA, et al. Small molecules block the polymerisation of $\mathrm{Z} \alpha 1$-antitrypsin and increase the clearance of intracellular aggregates. J Med Chem. 2007;50(22):5357-5363. doi: https://doi.org/10.1021/jm070687z

69. GlaxoSmithKline. Discovery partnerships with academia--Case studies: University College London collaboration aims to treat alpha-1 antitrypsin deficiency. GlaxoSmithKline website. http:// www.dpac.gsk.com/case-studies-universitycollegelondon.html Accessed Janaury 2018.

70. Tan L, Perez J, Mela M, et al. Characterising the association of latency with a1-antitrypsin polymerisation using a novel monoclonal antibody. Int J Biochem Cell Biol. 2015;58:81-91. doi: https://doi.org/10.1016/j.biocel.2014.11.005

71. Ordonez A, Pérez J, Tan L, et al. A single-chain variable fragment intrabody prevents intracellular polymerisation of $\mathrm{Z}$ a1-antitrypsin. FASEB J. 2015;29:2667-26678. doi: https://doi.org/10.1096/fj.14-267351

72. Irving JA, Miranda E, Haq I, et al. An antibody raised against a pathogenic serpin variant induces mutant-like behaviour in the wild-type protein. Biochem J. 2015;468(1):99-108. doi: https://doi.org/10.1042/BJ20141569

73. Motamedi-Shad N, Jagger AM, Liedtke M, et al. An antibody that prevents serpin polymerisation acts by inducing a novel allosteric behaviour. Biochem J. 2016;473(19):3269-3290. doi: https://doi.org/10.1042/BCJ20160159

74. Ding J, Yannam GR, Roy-Chowdhury N, et al. Spontaneous hepatic repopulation in transgenic mice expressing mutant human a1-antitrypsin AAT by wild-type donor hepatocytes. $J$ Clin Invest. 2011;121(5):1930-1934. doi: https://doi.org/10.1172/JCI45260

75. Rashid ST, Corbineau S, Hannan N, et al. Modeling inherited metabolic disorders of the liver using human induced pluripotent stem cells. J Clin Invest. 2010;120(9):3127-3136. doi: https://doi.org/10.1172/JCI43122

76. Wilson AA, Yin L, Liesa M, et al. Emergence of a stage-dependent human liver disease signature with directed differentiation of alpha-1 antitrypsin-deficient iPS cells. Stem Cell Reports. 2015;4(5):873-885.

doi: https://doi.org/10.1016/j.stemcr.2015.02.021

77. Yusa K, Rashid ST, Strick-Marchand H, et al. Targeted gene correction of a1-antitrypsin deficiency in induced pluripotent stem cells. Nature. 2011;478:391-394.

doi: https://doi.org/10.1038/nature10424
78. Baligar P, Kochat V, Arindkar SK, et al. Bone marrow stem cell therapy partially ameliorates pathological consequences in livers of mice expressing mutant human a1-antitrypsin. Hepatology. 2017;65(4):1319-1335. doi: https://doi.org/10.1002/hep.29027 